\title{
Project Energize: whole-region primary school nutrition and physical activity programme; evaluation of body size and fitness 5 years after the randomised controlled trial
}

\author{
Elaine Rush ${ }^{1 *}$, Stephanie McLennan ${ }^{2}$, Victor Obolonkin ${ }^{1}$, Alain C. Vandal ${ }^{3,4}$, Michael Hamlin $^{5}$, \\ David Simmons ${ }^{6}$ and David Graham ${ }^{7}$ \\ ${ }^{1}$ Centre for Child Health, Faculty of Health and Environmental Sciences, Auckland University of Technology, \\ Auckland, New Zealand \\ ${ }^{2}$ Sport Waikato, Hamilton, New Zealand \\ ${ }^{3}$ Faculty of Health and Environmental Sciences, Research Office, Auckland University of Technology, \\ Private Bag 92006, Auckland 1142, New Zealand \\ ${ }^{4}$ Centre for Clinical Research and Effective Practice, Auckland, New Zealand \\ ${ }^{5}$ Department of Social Science Parks Recreation Tourism and Sport, Lincoln University, Christchurch, New Zealand \\ ${ }^{6}$ Institute of Metabolic Science, Cambridge University Hospitals NHS Foundation Trust, Cambridge, England, UK \\ ${ }^{7}$ Child Health, Waikato Hospital, Hamilton, New Zealand
}

(Submitted 6 December 2012 - Final revision received 15 May 2013 - Accepted 18 June 2013 - First published online 19 July 2013)

\section{Abstract}

Project Energize, a region-wide whole-school nutrition and physical activity programme, commenced as a randomised controlled trial (RCT) in the period 2004-6 in 124 schools in Waikato, New Zealand. In 2007, sixty-two control schools were engaged in the programme, and by 2011, all but two of the 235 schools in the region were engaged. Energizers (trained nutrition and physical activity specialists) work with eight to twelve schools each to achieve the goals of the programme, which are based on healthier eating and enhanced physical activity. In 2011, indices of obesity and physical fitness of 2474 younger (7.58 (sD 0.57) years) and 2330 older (10.30 (sD 0.51) years) children attending 193 of the 235 primary schools were compared with historical measurements. After adjusting for age, sex, ethnicity, socio-economic status (SES) and school cluster effects, the combined prevalence of obesity and overweight among younger and older children in 2011 was lower by 31 and 15\%, respectively, than that among 'unEnergized' children in the 2004 to 2006 RCT. Similarly, BMI was lower by $3.0 \%(95 \%$ CI $-5.8,-1 \cdot 3)$ and $2.4 \%(95 \%$ CI $-4.3,-0.5)$. Physical fitness (time taken to complete a $550 \mathrm{~m}$ run) was significantly higher in the Energized children ( 13.7 and $11.3 \%$, respectively) than in a group of similarly aged children from another region. These effects were observed for boys and girls, both indigenous Māori and non-Māori children, and across SES. The long-term regional commitment to the Energize programme in schools may potentially lead to a secular reduction in the prevalence of overweight and obesity and gains in physical fitness, which may reduce the risk of developing obesity and type 2 diabetes.

Key words: Children: Schools: Obesity: Prevention: Interventions: Māori

In New Zealand (NZ), the prevalence of overweight and obesity defined by international ${ }^{(1)}$ cut-offs for BMI is significantly higher in Māori (40\%) and Pacific (60\%) children than in their European counterparts $(24 \%)^{(2)}$. Higher rates can also be found in more deprived areas ${ }^{(2,3)}$ and from 10 years of age ${ }^{(2,3)}$ in girls than in boys.

Evidence for the effectiveness of long-term school-based interventions for reduction of obesity is limited ${ }^{(4,5)}$, possibly due to the relatively short duration of randomised controlled trials (RCT) and a focus on the characteristics of individuals who consent to be measured twice ${ }^{(6)}$. The duration of a RCT is influenced by both the practicality and ethics of having schools and their students as controls over a longer term ${ }^{(7)}$. It is important that evidence from trials be translated into sustainable public health actions and that evidence of a wider and longer-term impact be obtained subsequently ${ }^{(8)}$. However, the reality of translating and evaluating physical activity and nutrition programmes in the long term in children requires measures that are 'contextual, practical and robust' ${ }^{(9)}$.

The Energize programme, a whole-school physical activity and nutrition intervention ${ }^{(10)}$ in the Waikato region, is a RCT that was implemented in sixty-two control and sixty-two

Abbreviations: NZ, New Zealand; RCT, randomised controlled trial; SDS, standard deviation score; SES, socio-economic status.

*Corresponding author: Professor E. Rush, fax +6429921 9960, email elaine.rush@aut.ac.nz 
intervention schools from 2004 to 2006. Body size and fatness (bioimpedance) of children aged 5 and 10 years were measured in 2004 and again in 2006. Measurements of body composition included age- and sex-specific BMI standard deviation scores (SDS), based on the British 1990 reference population ${ }^{(11)}$ and international ${ }^{(1)}$ criteria for body size. The selection of these age groups, in 2004, was pragmatically based on the funding available, the ethnic and socio-economic diversity of the children and our ability to follow over 2 years children who were mostly pre-adrenarchal (5-7 years) and pre-pubertal (10-12 years). In younger children, a reduction in the accumulation of body fat, and in older children, a reduced rate of rise in systolic blood pressure was observed $^{(12)}$. The regional primary school population is approximately 42000 children (36\% Māori, 64\% rural, and $55 \%$ below the median of the national socio-economic classification for schools), attending 233 schools including $10 \%$ of the land area and $10 \%$ of the child population of NZ.

The Energize programme has, therefore, been in place since 2005. The 2011 measurements represent up to 6 years of engagement, implementation and translation within a school. During this time, it has been reported in Australia that child obesity levels, although high, appear to have levelled off ${ }^{(13)}$. The apparent levelling effect has been critiqued $^{(14)}$ in relation to sample size, response bias, changes in the sampling method and frames, data drawn from geographically narrow areas and use of thresholds such as the International Obesity Task Force-defined obesity classification, which may miss changes in the severity of obesity. In NZ, there has been a rise in adult obesity between 2006 and $2010^{(15)}$ and a continual rise in gestational diabetes, particularly in Māori ${ }^{(16,17)}$, which presages a rise in childhood obesity. We, therefore, aimed to establish what effect the Energize project was having on the obesity and physical fitness of Waikato children, given the obesogenic background in which these children live.

In the absence of a contemporaneous control group in the Waikato region, a decision was made to compare the 2011 Energized children aged 7 and 10 years with the control children measured in the 124 RCT schools in 2004 (10-year-olds) and the sixty-two control schools in 2006 (7-year-olds). No fitness measures had been recorded previously for Waikato children, so comparisons of measures for Canterbury children between 2001 and $2007^{(18,19)}$ were proposed.

In 2011, our aim was to determine the effect of a physical activity and nutrition programme on the indices of obesity, BMI and physical fitness ( $550 \mathrm{~m}$ run) of children aged 7 and 10 years in comparison with those of children measured 6-11 years earlier.

\section{Methods}

The methodology and outcomes of the 2004-6 RCT have been published elsewhere ${ }^{(10,12)}$. Project Energize was rolled out in all the regional schools in the Waikato region from 2006. The 2011 evaluation has used the 2006 anthropometric measurements from the RCT control groups as historical comparisons ${ }^{(20)}$. The programme goals (http://www.projectenergize.org.nz/what_ we_do_goals_.cfm), overall project architecture and delivery method have remained unchanged since 2005. Efficiencies, resources and process are continuously improved and refined.

The 'younger' and 'older' children surveyed in 2011 were aged 6-8 and 9-11 years as the invitation to participate was by school class. Ethnicity was recorded from parental and school reports, and ethnicity was assigned to one of the four hierarchical groups (Māori, Pacific, European and 'other'). Socio-economic status (SES) was calculated via the use of school deciles, which were obtained from a national register $^{(21)}$. A scale from 1 to 10 was used, with 1 being linked to the lowest $10 \%$ of affluence and 10 to the highest $10 \%$. This measure of SES was further divided into three categories: low (school deciles 1-3); medium (school deciles 4-7); high (school deciles 8-10). The classification of rurality was based on the location of schools. Schools located in the Tokoroa and Hamilton areas were classified as urban, with the remainder being classified as rural. Schools were enrolled sequentially, from sixty-two programme schools in 2005 to 117 schools in 2007-8 (including the original RCT control schools and in the order of greatest social disadvantage first), and then gradually up to 233 of the 235 schools in the region by the start of 2010. In 2011, two of the 235 schools had declined to engage in the programme and were not included in this evaluation. Given a four-term school year, at the time of this evaluation, schools had been enrolled from as few as six school terms to as many as twenty-six school terms (Fig. 1). Only schools ( $n$ 193) that had been actively engaged with the programme since July 2009, i.e. at least 18 months, were invited to participate. The single measure of dose available was months of engagement of each school with the programme.

The present study was conducted according to the guidelines laid down in the Declaration of Helsinki, and all procedures involving human subjects were approved by the 'Northern Y Regional Ethics Committee' with all usual caregivers and children providing written and signed informed consent. The original trial (2004-6) was registered in the Australasian Clinical Trials Registry (ACTRN: 12610000132044).

\section{Physical measurements}

Children wore light clothing and no shoes. Height (portable height scale, Invicta; Modern Teaching Aids) and weight (portable electronic scale, TIHD316 and Soehnle 7505; Wedderburn) were measured to $\pm 0.5 \mathrm{~cm}$ and $\pm 0.5 \mathrm{~kg}$, respectively. All measures were recorded twice, and where tolerance was exceeded, a third measurement was taken. BMI was calculated in $\mathrm{kg} / \mathrm{m}^{2}$. Exact age was recorded as the difference between date of birth and date of measurement. Teams of Energizers and public health nurses, trained in all the methods of measurement, recorded the measurements on site in the schools. The methods of measurement were identical in the RCT and the present study.

Children were asked to complete a standardised $550 \mathrm{~m}$ run as fast as they could. First released by the American Alliance for Health, Physical Education and Recreation in 1958 as part of the 'Youth Fitness Test', the 600-yard $(550 \mathrm{~m})$ run was developed as a measure of cardiorespiratory endurance for children 


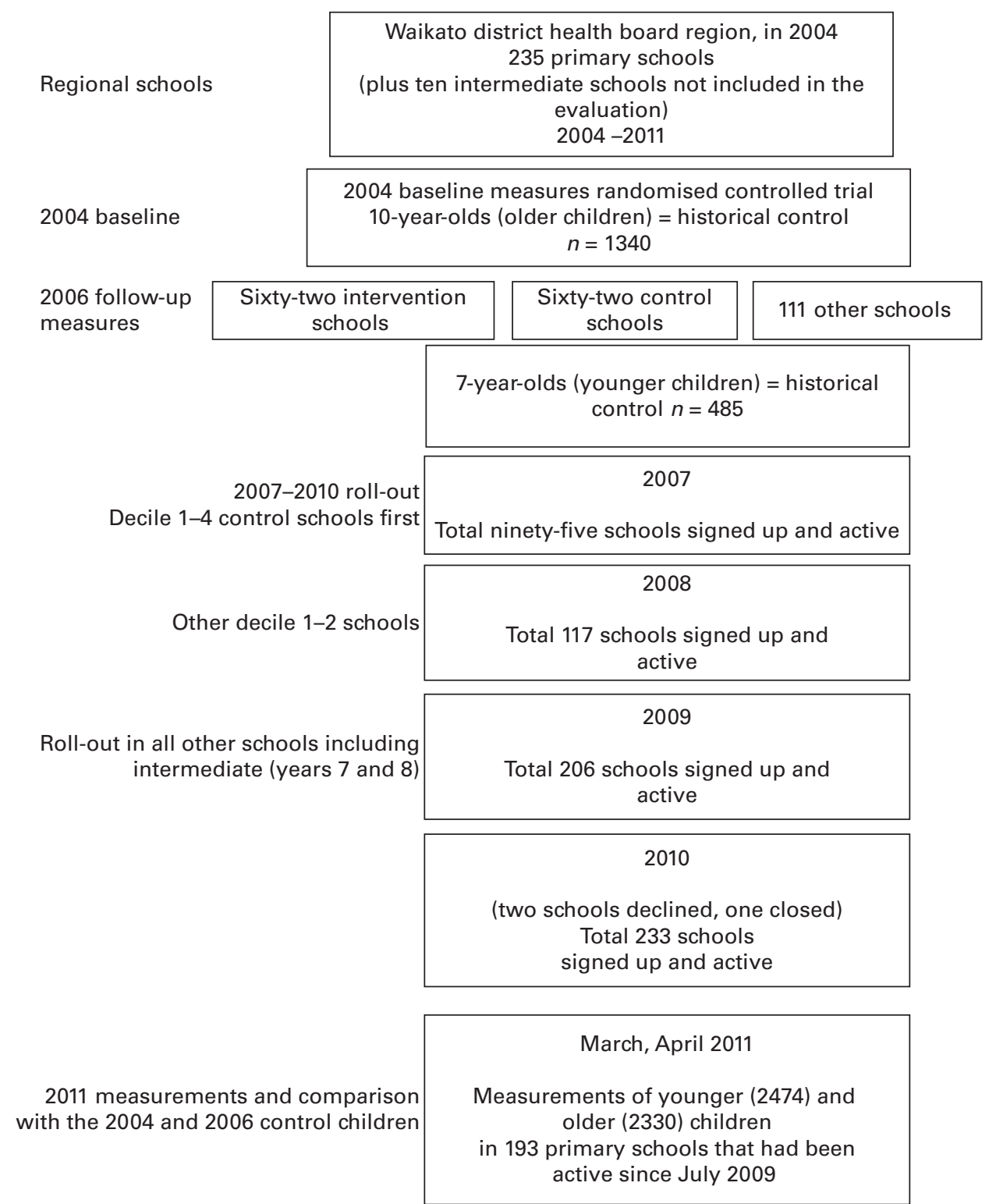

Fig. 1. Project Energize: inception as a randomised controlled trial in 2004 and process of roll-out in regional primary schools leading up to the evaluation in 2011.

and adolescents. Running tests of at least $550 \mathrm{~m}$ are required to adequately measure aerobic endurance in children ${ }^{(22,23)}$, and time to complete the $550 \mathrm{~m}$ run is positively related to cardiorespiratory fitness as measured by maximal oxygen uptake ${ }^{(24)}$. This measurement was taken after completion of the RCT to address observations that the fundamental movement skills of children had improved in Energized schools ${ }^{(25)}$.

\section{Selection of comparison data}

Anthropometric comparison measurements were made in the younger control school children at the end of the RCT (2006) and in all older RCT participants before the start of the intervention (2004). BMI SDS were calculated using the British 1990 reference population ${ }^{(26)}$. The British reference values were used due to a substantial proportion of $\mathrm{NZ}$ people, including Māori, having some British ancestry and because there are no comparable NZ tables. On the basis of BMI for age and sex, the prevalence of thinness, normal weight, overweight and obesity was determined according to the International Obesity Task Force reference for children ${ }^{(1)}$ Times taken to run $550 \mathrm{~m}$ were compared with the historical measurements of 664 children attending seven primary schools (decile range 2-10) in Canterbury, NZ, between 2001 and $2007^{(18,19)}$. The comparison of run speeds did not include the ethnicity or rurality factor because ethnicity data were only available for 376 of 664 children (57\%) and rurality was not recorded.

\section{Intervention components}

A standardised Memorandum of Agreement with each school fully describes the designated responsibilities of the school and the regional sports organisation (Sport Waikato), and 
the school is informed that it would participate in the evaluation of the programme. 'Team Energize' are teachers or graduates of exercise/nutrition or physical education, employed by Sport Waikato to support the delivery and development of the programme in each school. Each year, a delegated representative for each school works with his or her Energizer to identify the nutrition and physical activity priorities of the school; a 'needs analysis' is undertaken and prioritised, and then an individualised action plan for the year, based on the goals of the Energize programme, is developed and delivered over the year. All physical (including sports) and nutrition activities within a school are coordinated through the Energizer, reducing the burden of multiple interactions with outside agencies on the school.

The team manager allocates Team Energize staff ('Energizers' $n$ 27) between eight and twelve schools each. From induction, every month, the 'Energizers' undergo team training in order to share experiences, resources and skills. The philosophy adopted is that Team Energize staff act as agents of change, not as additional teaching staff. For example, Team Energize staff might provide professional development to the teachers using reciprocal modelling of classes and on how to use support materials provided. Classes modelled include fundamental movement skills training, ideas for 'huff and puff' fitness activities, modified games, ball activities and sports-related games, where the focus is on keeping the children moving as much as possible throughout each session. Teachers request, and are then provided with ideas for the management and control of children during physical activity sessions. Energizers promote active transport, lunchtime games, bike days and leadership training for students to be leaders of physical activities before and after school.

Energizers assist each school with the implementation of a range of healthy eating initiatives. These include canteen makeovers to remove pastry-based pies and 'big cookies' and add filled rolls, fruit and low-fat yogurt. Healthy fundraising is promoted with sales of water, milk, soup, bread rolls, fruit and non-food items instead of chocolate, sweets, sausages and sugary drinks. Support is also given to class teachers (by the Energizers) in the form of curriculum-based material, which provides information on the benefits of replacing sugary drinks with water and milk, the importance of eating breakfast, and the modelling of the preparation of healthy lunches and snacks on a budget. The project is aligned with other national and regional activities such as water safety.

Nutrition 'nuggets' are also provided every week in the school newsletter. These include a series of thirty smart swaps (e.g. replacing instant noodles with baked beans and potato crisps with popcorn) and lunch box makeovers to include sandwiches and fruit and demonstrate 'everyday, sometimes and occasional' foods. There is a home-school link programme that provides opportunities for parents to attend information and practical sessions. During the same weeks, all classes in the school receive integrated nutrition lessons. Fridge magnets and laminated cards that reinforce the nutrition goals are given to all children, and they are encouraged to put these on their fridges at home. Further support is provided through a range of activities, such as gala open days and edible gardens, healthy fund-raising and parent-teacher evenings with a dietitian to raise awareness of healthier choices of food. Furthermore, the average intervention cost for each child is low: approximately New Zealand \$45 for each school year.

\section{Statistical analysis}

Descriptive data of the children are presented as means and standard deviations or percentages, separately for the 'younger' and 'older' groups. The outcomes consisted of five continuous quantities (BMI, BMI SDS, height SDS, weight SDS and time taken to run $550 \mathrm{~m}$ ) and one dichotomous indicator of overweight or obesity obtained by categorising the International Obesity Task Force grade into two levels: normal (grade $\leq 0$ ) and overweight (grade $>0$ ). The natural logarithms of the continuous outcomes were used for regression purposes to decrease the right skewness of the residuals.

Differences between the Energize and historical data were estimated using mixed model regression as point estimates and as 95\% CI. CI were back-transformed, and they are expressed as percentage changes (i.e. change in the 2011 measurements relative to the 2006/2004 measurements). Generalised linear mixed models (normal family for continuous outcomes and binomial family for dichotomous outcomes) were used to analyse the differences between outcomes in the Energized children (2011) and those in historical children, i.e. the Energize factor effects (the 'Energize' factor is a simple dichotomous indicator of a 2011 Energized child or a child belonging to the comparison group). An initial model was obtained by fitting each outcome to the covariates age (in months), ethnicity, sex, socio-economic decile and rurality indicator, overweight or obesity indicator and time taken to run for BMI and ethnicity, sex, socio-economic decile and rurality indicator for SDS. Factors were removed stepwise in the descending order of $P$ values whenever they were found to be non-significant, yielding the null model. This null model was compared with a null-plus-Energize model (or 'Energize model') to estimate the effect of the Energize factor. After establishing the significance of the 2011 Energize factor, each originally removed covariate was entered into the Energize model, by itself and in interaction with the Energize factor. None of the covariates (or interactions) thus included was found to be significant (Table 1). The Energize model accounted for school clustering by including schools as random effects. Unequal variance of the Pacific group was accounted for in the model.

All tests of models were deviance based. All tests were two tailed and carried out at the 5\% significance level, and all estimates are reported as percentage changes in the 2011 measurements relative to the historical measurements and $95 \%$ CI of the change. Bonferroni-corrected CI were also computed, based on the twelve comparisons resulting from the two age groups and six selected outcomes. Model selection process and model validation were carried out separately for all the outcome measurements. The resultant null models included ethnicity and SES in all cases, to which were added age in months for BMI and combined overweight or obesity 
Table 1. Covariates entered into the null model for each outcome considered

\begin{tabular}{lccccc}
\hline Outcomes & Ethnicity & SES & Age & Sex & Rurality \\
\hline Height SDS* & $\mathrm{X}$ & $\mathrm{X}$ & & & \\
Weight SDS* $^{*}$ & $\mathrm{X}$ & $\mathrm{X}$ & & & \\
BMI SDS* & $\mathrm{X}$ & $\mathrm{X}$ & $\mathrm{X}$ & & \\
BMI $\left(\mathrm{kg} / \mathrm{m}^{2}\right)^{\star}$ & $\mathrm{X}$ & $\mathrm{X}$ & $\mathrm{X}$ & & \\
Overweight or obese† & $\mathrm{X}$ & $\mathrm{X}$ & $\mathrm{X}$ & $\mathrm{X}$ & \\
Time to run $550 \mathrm{~m}(\mathrm{~s})^{\star}$ & & & \\
\hline
\end{tabular}

SES socio-economic status; SDS, standard deviation score.

* Log-transformed.

† Dichotomous outcomes (mixed logistic regression): SDS and SES.

outcomes and age in months and sex for the time to complete the $550 \mathrm{~m}$ run. $\mathrm{R}$ v2.12 packages (www.r-project.org) were used for the statistical analysis ${ }^{(27)}$.

\section{Results}

In 2011, $233(99 \cdot 1 \%)$ of the 235 primary schools in the Waikato District Health Board region had signed the Memorandum of Agreement with Sport Waikato and were engaged in the Energize programme.

In 2011, parental and child consent was obtained for 5466 children and subsequently in 5306 children (97\%), from 193 schools, measurements were taken. After removing incorrect and incomplete measures, 4804 children aged 6-11 years were categorised by age: younger aged $6-8$ years ( $n$ 2474; $35 \%$ Māori and 55\% European) and older aged 9-11 years ( $n$ 2330; 36\% Māori and 54\% European). In 2010, the majority of Waikato children were identified by parents on enrolment as Māori (34\%) or European (55\%, Ministry of Education records). Proportionally more Māori children agreed to participate in the measurement sessions in 2011 than in the 2004-6 RCT. In 2011, the number of children from each participating school ranged from 1 to 171 and was in proportion to the school rolls (all ages), which ranged from 8 to 717 . The proportion of Māori children attending a school ranged from 0 (in a school having <25 Māori children) to 100\%. (Māori attendance was observed in thirteen schools with rolls ranging between 13 and 164.)

Consent (parent and child) to be measured was obtained from $46 \%$ of the eligible children aged 7 years and $45 \%$ of those aged 10 years attending the 193 schools evaluated. For the 7 - and 10-year-olds, the rates were 37 and $42 \%$ for the Māori children and 50 and $45 \%$ for the European children, respectively. The number of children attending each school was determined from school-specific Ministry of Education data by age and ethnicity.

The mean age of the 2011 children was less ( 1.5 months for the younger children and 3.6 months for the older children) than that of the Energized historical comparison ('control') children (Table 2), but the children did not differ with regard to mean height (95\% CI for the Energize-Control difference (95\% CI $-0.25,1.75)$ ) (Table 3). Overall and within the sexes for both age groups, mean values for weight, BMI and prevalence of overweight or obesity were less than the historical comparisons (Table 3).
Run information from the Canterbury region collected between 2001 and 2007 was available for 664 children, aged 6-11 years, $53 \cdot 2 \%$ girls from schools classified from decile 2 to decile 10 . For the $56.6 \%$ for whom ethnicity was observed, $11 \cdot 2 \%$ were Māori or Pacific, $82 \cdot 7 \%$ European and $6 \cdot 1 \%$ other.

Comparison using the age- and sex-specific British SDS adjusted by ethnicity and SES showed that within the age groups, the 2011 children were taller and lighter and their BMI was less than the historical comparisons (Table 4).

After adjusting for age, ethnicity and decile and accounting for school effect within the age groups (Table 3), BMI was lower in the 2011 Energized children. In 2011, younger children were $31 \%$ and older children were $15 \%$ less likely to be obese or overweight than those in the historical/'unEnergized' schools (Table 4). The prevalence of thinness was not different (not shown).

Similarly, the time taken to complete the $550 \mathrm{~m}$ run was 14 and $11 \%$ lower, respectively, than the historical Canterbury comparisons (Table 4) after accounting for age, sex and SES of the school.

No significant interaction between the Energize factor and either ethnicity and/or socio-economic decile was observed for any of the outcomes measured (obesity indicator, BMI, time taken to run $550 \mathrm{~m}$ and SDS), suggesting that Project Energize had a similar relative effect among the different ethnic and SES groups. The number of months of engagement of the school with the programme was not a predictor.

\section{Discussion}

The primary aim of the Energize programme was to slow the rate of excess weight gain in children through a population-based public health service. At the time of this evaluation, all except two schools (99.1\%) had adopted the programme, and in 2012, these schools requested and received the service. This reflects whole-region adoption, reach and implementation.

After accounting for all the possible covariates and school, both BMI and prevalence of overweight or obesity in 2011 were less than those among the comparison children at the beginning (2004 older children) and end (2006 younger children) of the 2004-6 RCT. There was no increase in the prevalence of thinness, suggesting successful targeting and reduction of the right skewness of the distribution of excess overweight or obesity rather than adding to underweight ${ }^{(28)}$. This programme was effective among groups that are often hard to reach, with favourable and statistically significant outcomes among those who identified themselves as Māori, across socio-economic groups and for both boys and girls. In addition, the measurement of fitness indicated that the Energized children were faster (approximately 10\%) than the historical comparison group. As far as we are aware of this is one of the few population-based interventions to be associated with apparent reductions in the prevalence of excess weight gain among children to date.

Furthermore, national health surveys among 5-14-year-olds have reported an increasing prevalence of overweight or obesity of $28.8 \%$ in $2002^{(29)}, 28.9 \%$ in $2006^{(2)}$ and $32.2 \%$ in 
Table 2. Baseline characteristics of the Energized and historical comparison children of the Waikato region (Mean values and standard deviations; percentages and $95 \%$ confidence intervals)

\begin{tabular}{|c|c|c|c|c|c|c|c|}
\hline \multirow[b]{2}{*}{ Characteristics } & \multirow[b]{2}{*}{ Exposure arm } & \multicolumn{2}{|c|}{ All } & \multicolumn{2}{|c|}{ Girls } & \multicolumn{2}{|c|}{ Boys } \\
\hline & & Younger & Older & Younger & Older & Younger & Older \\
\hline \multirow[t]{2}{*}{$n$} & Energized & 2474 & 2330 & 1278 & 1251 & 1196 & 1079 \\
\hline & Comparison & 485 & 1340 & 236 & 649 & 249 & 691 \\
\hline \multirow[t]{8}{*}{ Age (years) } & Energized & & & & & & \\
\hline & Mean & 7.58 & $10 \cdot 30$ & 7.58 & $10 \cdot 29$ & 7.58 & $10 \cdot 32$ \\
\hline & SD & 0.57 & 0.51 & 0.57 & 0.52 & 0.57 & 0.50 \\
\hline & Comparison & & & & & & \\
\hline & Mean & $7 \cdot 71$ & $10 \cdot 66$ & $7 \cdot 74$ & $10 \cdot 64$ & 7.69 & $10 \cdot 69$ \\
\hline & SD & 0.31 & 0.34 & 0.30 & 0.35 & 0.31 & 0.33 \\
\hline & Difference (\%) & $-2 \cdot 3$ & -3.6 & -11.3 & -8.9 & $-9 \cdot 3$ & -11.4 \\
\hline & $95 \% \mathrm{Cl}^{*}$ & $-1 \cdot 6,-3 \cdot 0$ & $-3.3,-3.9$ & $-9 \cdot 1,-13 \cdot 4$ & $-7 \cdot 4,-10 \cdot 3$ & $-7 \cdot 1,-11 \cdot 6$ & $-10 \cdot 0,-12 \cdot 7$ \\
\hline \multicolumn{8}{|l|}{ Ethnicity (\%) } \\
\hline \multirow[t]{2}{*}{ European } & Energized & $54 \cdot 3$ & 53.7 & $53 \cdot 8$ & $54 \cdot 1$ & $55 \cdot 0$ & $53 \cdot 2$ \\
\hline & Comparison & $65 \cdot 4$ & 62.9 & 63.5 & 63.0 & $67 \cdot 3$ & $62 \cdot 7$ \\
\hline \multirow[t]{2}{*}{ Māori } & Energized & 35.6 & $36 \cdot 6$ & 35.5 & $36 \cdot 1$ & 35.7 & $37 \cdot 2$ \\
\hline & Comparison & $26 \cdot 6$ & $28 \cdot 8$ & $27 \cdot 8$ & $28 \cdot 2$ & 25.5 & $29 \cdot 4$ \\
\hline \multirow[t]{2}{*}{ Pacific } & Energized & $6 \cdot 3$ & $6 \cdot 1$ & 6.5 & $6 \cdot 3$ & $6 \cdot 0$ & $5 \cdot 7$ \\
\hline & Comparison & $5 \cdot 1$ & $5 \cdot 8$ & $6 \cdot 1$ & $6 \cdot 1$ & $4 \cdot 2$ & 5.5 \\
\hline \multirow{2}{*}{ Other } & Energized & $3 \cdot 8$ & $3 \cdot 6$ & $4 \cdot 3$ & 3.4 & 3.4 & $3 \cdot 8$ \\
\hline & Comparison & $2 \cdot 9$ & 2.5 & $2 \cdot 7$ & $2 \cdot 6$ & 3.0 & $2 \cdot 4$ \\
\hline \multicolumn{8}{|c|}{ Socio-economic status (\%) } \\
\hline \multirow[t]{2}{*}{ Low } & Energized & 38.0 & 34.6 & $40 \cdot 6$ & $32 \cdot 4$ & 37.4 & $37 \cdot 0$ \\
\hline & Comparison & $37 \cdot 1$ & $38 \cdot 1$ & 37.4 & 37.9 & $39 \cdot 6$ & 37.4 \\
\hline \multirow[t]{2}{*}{ Medium } & Energized & $41 \cdot 7$ & $40 \cdot 1$ & $37 \cdot 1$ & 44.5 & $40 \cdot 3$ & 38.8 \\
\hline & Comparison & 31.4 & $37 \cdot 7$ & 38.4 & $37 \cdot 3$ & $37 \cdot 2$ & 33.9 \\
\hline \multirow[t]{2}{*}{ High } & Energized & $20 \cdot 3$ & $25 \cdot 3$ & $22 \cdot 3$ & $23 \cdot 1$ & $22 \cdot 3$ & $24 \cdot 2$ \\
\hline & Comparison & 31.6 & $24 \cdot 1$ & 24.2 & $24 \cdot 8$ & 23.3 & 28.9 \\
\hline
\end{tabular}

${ }^{*} 95 \% \mathrm{Cl}$ (accounting for clustering) for the percentage change in the 2011 children relative to the 2006 (younger) or 2004 (older) children.

$2008^{(30)}$, compared with our measures of $19 \cdot 5 \%$ in younger children and $26 \cdot 6 \%$ in older children. This favourable difference was also observed among the Māori children, where the 2011 prevalence was $27 \cdot 5 \% / 38 \cdot 6 \%$ among the younger/ older children compared with the national prevalence of $38.8 \%$ in $2002^{(29)}$ and $37 \cdot 2 \%$ in $2006^{(2)}$ for $5-14$-year-olds. Concurrently, the prevalence of overweight and obesity in $\mathrm{NZ}$ adults, including the parents of these children, has also shown a steady increase from 1997 to $2009^{(2,3,15)}$. The recently published 2011/2012 National Health Survey ${ }^{(31)}$ has reported that the prevalence of obesity has significantly increased from 8.4 to $10.9 \%$ in children aged $2-14$ years. The prevalence of overweight has not been reported.

The functional measure of physical fitness indicated substantial increases in speed compared with historical Canterbury comparisons for girls and boys aged 6-11 years. Since the $1980 \mathrm{~s}$, there has been a documented decline in fitness in youth both in $\mathrm{NZ}^{(18)}$ and internationally ${ }^{(32)}$. Coupled with the concurrent increase in body size and fatness, it could be predicted that the 2011 children would not be faster,

Table 3. Outcome-related measurement summaries of the Energized and historical comparison children

(Mean values and standard deviations; percentages)

\begin{tabular}{|c|c|c|c|c|c|c|c|c|c|c|c|c|c|}
\hline \multirow[b]{3}{*}{ Characteristics } & \multirow[b]{3}{*}{ Exposure arm } & \multicolumn{4}{|c|}{ All } & \multicolumn{4}{|c|}{ Girls } & \multicolumn{4}{|c|}{ Boys } \\
\hline & & \multicolumn{2}{|c|}{ Younger } & \multicolumn{2}{|c|}{ Older } & \multicolumn{2}{|c|}{ Younger } & \multicolumn{2}{|c|}{ Older } & \multicolumn{2}{|c|}{ Younger } & \multicolumn{2}{|c|}{ Older } \\
\hline & & Mean & SD & Mean & SD & Mean & SD & Mean & SD & Mean & SD & Mean & SD \\
\hline \multirow[t]{2}{*}{ Height (cm) } & Energized & $126 \cdot 9$ & 6.5 & $142 \cdot 6$ & $7 \cdot 1$ & $126 \cdot 5$ & $6 \cdot 6$ & $142 \cdot 3$ & $7 \cdot 2$ & $127 \cdot 4$ & 6.5 & 143.0 & $7 \cdot 0$ \\
\hline & Comparison & $126 \cdot 9$ & $5 \cdot 8$ & 143.9 & 6.9 & $126 \cdot 5$ & $6 \cdot 0$ & $143 \cdot 9$ & $7 \cdot 2$ & $127 \cdot 3$ & $5 \cdot 6$ & 144.0 & 6.5 \\
\hline \multirow[t]{2}{*}{ Weight (kg) } & Energized & 27.4 & $6 \cdot 1$ & 38.4 & $9 \cdot 6$ & $27 \cdot 3$ & $6 \cdot 4$ & 38.4 & $9 \cdot 7$ & 27.42 & 5.8 & 38.40 & $9 \cdot 7$ \\
\hline & Comparison & $28 \cdot 2$ & 5.9 & $40 \cdot 2$ & $9 \cdot 8$ & $28 \cdot 1$ & $5 \cdot 8$ & $40 \cdot 6$ & $10 \cdot 3$ & $28 \cdot 28$ & 5.9 & 39.90 & 9.4 \\
\hline \multirow[t]{2}{*}{ BMI $\left(\mathrm{kg} / \mathrm{m}^{2}\right)$} & Energized & $16 \cdot 83$ & $2 \cdot 5$ & $18 \cdot 7$ & 3.5 & $16 \cdot 9$ & $2 \cdot 7$ & $18 \cdot 8$ & $3 \cdot 6$ & $16 \cdot 8$ & $2 \cdot 4$ & $18 \cdot 61$ & 3.5 \\
\hline & Comparison & $17 \cdot 36$ & $2 \cdot 6$ & $19 \cdot 3$ & 3.6 & $17 \cdot 4$ & $2 \cdot 4$ & $19 \cdot 4$ & 3.6 & $17 \cdot 3$ & $2 \cdot 7$ & $19 \cdot 11$ & 3.5 \\
\hline \multirow{2}{*}{$\begin{array}{l}\text { Combined } \\
\text { overweight/obesity }(\%)^{*}\end{array}$} & Energized & \multicolumn{2}{|c|}{19.5} & \multicolumn{2}{|c|}{$26 \cdot 6$} & \multicolumn{2}{|c|}{$22 \cdot 2$} & \multicolumn{2}{|c|}{$27 \cdot 4$} & \multicolumn{2}{|c|}{$16 \cdot 5$} & \multicolumn{2}{|c|}{25.8} \\
\hline & Comparison & \multicolumn{2}{|c|}{$23 \cdot 8$} & \multicolumn{2}{|c|}{$27 \cdot 8$} & \multicolumn{2}{|c|}{$26 \cdot 3$} & \multicolumn{2}{|c|}{29.4} & \multicolumn{2}{|c|}{21.4} & \multicolumn{2}{|c|}{$26 \cdot 2$} \\
\hline \multirow{2}{*}{$\begin{array}{l}\text { Time taken to } \\
\text { run } 550 \mathrm{~m}(\mathrm{~s})\end{array}$} & Energized & $183 \cdot 2$ & 28.9 & $164 \cdot 2$ & $28 \cdot 8$ & $188 \cdot 6$ & $27 \cdot 5$ & $169 \cdot 7$ & $27 \cdot 9$ & $177 \cdot 4$ & $29 \cdot 1$ & $158 \cdot 0$ & 28.5 \\
\hline & Comparison & $212 \cdot 7$ & $47 \cdot 1$ & 179.8 & $47 \cdot 0$ & $220 \cdot 3$ & 53.5 & $191 \cdot 1$ & $51 \cdot 1$ & 204.4 & 37.5 & $165 \cdot 6$ & $37 \cdot 0$ \\
\hline
\end{tabular}

* Overweight or obesity classification based on Cole's cut-offs. 
Table 4. Unadjusted and adjusted OR and relative differences in outcome measures between the Energized and historical comparison children, with nominal and Bonferroni-adjusted $\mathrm{Cl}^{*}$, by age group $\dagger$

(Percentages and $95 \%$ confidence intervals)

\begin{tabular}{|c|c|c|c|c|c|c|c|c|}
\hline \multirow[b]{3}{*}{ BMI } & \multicolumn{4}{|c|}{ Younger } & \multicolumn{4}{|c|}{ Older } \\
\hline & \multicolumn{2}{|c|}{ Unadjusted } & \multicolumn{2}{|c|}{ Adjusted } & \multicolumn{2}{|c|}{ Unadjusted } & \multicolumn{2}{|c|}{ Adjusted } \\
\hline & $\%$ & $95 \% \mathrm{Cl}$ & $\%$ & $95 \% \mathrm{Cl}$ & $\%$ & $95 \% \mathrm{Cl}$ & $\%$ & $95 \% \mathrm{Cl}$ \\
\hline $\begin{array}{l}\text { Relative difference in meansł } \\
\text { Bonferroni corrected }\end{array}$ & -3.6 & $\begin{array}{l}-5 \cdot 1,-2 \cdot 0 \\
-5 \cdot 8,-1 \cdot 3\end{array}$ & $-3.0 \S$ & $\begin{array}{l}-4 \cdot 3,-1 \cdot 7 \\
-4 \cdot 9,-1 \cdot 1\end{array}$ & $-3 \cdot 2$ & $\begin{array}{l}-4 \cdot 6,-1 \cdot 8 \\
-5 \cdot 2,-1 \cdot 2\end{array}$ & $-2.4 \S$ & $\begin{array}{l}-3 \cdot 7,-1 \cdot 1 \\
-4 \cdot 3,-0 \cdot 5\end{array}$ \\
\hline Combined overweight and obesity & & & & & & & & \\
\hline $\begin{array}{l}\text { OR } \\
\text { Bonferroni corrected }\end{array}$ & 0.72 & $\begin{array}{l}0.60,0.92 \\
0.55,1.01\end{array}$ & $0.69 \S$ & $\begin{array}{l}0.54,0.88 \\
0.47,0.97\end{array}$ & 0.93 & $\begin{array}{l}0 \cdot 79,1 \cdot 10 \\
0 \cdot 73,1 \cdot 18\end{array}$ & $0.85 \S$ & $\begin{array}{l}0.72,1.00 \\
0.66,1.07\end{array}$ \\
\hline Time taken to run $550 \mathrm{~m}$ & & & & & & & & \\
\hline $\begin{array}{l}\text { Relative difference in means } \| \\
\text { Bonferroni-corrected } 95 \% \mathrm{Cl}\end{array}$ & $-12 \cdot 8$ & $\begin{array}{l}-15 \cdot 2,-11 \cdot 3 \\
-16 \cdot 3,-10 \cdot 6\end{array}$ & $-13 \cdot 7 \emptyset$ & $\begin{array}{l}-15 \cdot 8,-12 \cdot 3 \\
-16 \cdot 8,-11 \cdot 7\end{array}$ & $-8 \cdot 1$ & $\begin{array}{r}-9 \cdot 9,-6 \cdot 6 \\
-10 \cdot 7,-5 \cdot 9\end{array}$ & -11.39 & $\begin{array}{l}-14 \cdot 1,-9 \cdot 0 \\
-15 \cdot 4,-7 \cdot 9\end{array}$ \\
\hline Height SDS* & & & & & & & & \\
\hline $\begin{array}{l}\text { Relative difference in means } \neq \\
\text { Bonferroni corrected }\end{array}$ & $3 \cdot 1$ & $\begin{array}{l}1 \cdot 1,5 \cdot 1 \\
0 \cdot 2,6 \cdot 0\end{array}$ & $2 \cdot 7^{\star \star}$ & $\begin{array}{r}0.7,4 \cdot 8 \\
-0.2,5 \cdot 8\end{array}$ & 1.9 & $\begin{array}{r}0.5,3.3 \\
-0.1,3.9\end{array}$ & $1 \cdot 2^{\star \star}$ & $\begin{array}{r}0.1,2 \cdot 6 \\
-0.4,3 \cdot 2\end{array}$ \\
\hline Weight SDS & & & & & & & & \\
\hline $\begin{array}{l}\text { Relative difference in meansł } \\
\text { Bonferroni corrected }\end{array}$ & $-2 \cdot 1$ & $\begin{array}{l}-4 \cdot 1,-0 \cdot 1 \\
-5 \cdot 0,0 \cdot 8\end{array}$ & $-2 \cdot 6^{\star \star}$ & $\begin{array}{l}-4 \cdot 4,-0 \cdot 7 \\
-5 \cdot 2,0 \cdot 2\end{array}$ & $-1 \cdot 3$ & $\begin{array}{l}-2 \cdot 7,0 \cdot 1 \\
-3 \cdot 3,0 \cdot 7\end{array}$ & $-2 \cdot 2^{* \star}$ & $\begin{array}{l}-3.5,-0.9 \\
-4.1,-0.3\end{array}$ \\
\hline BMI SDS & & & & & & & & \\
\hline $\begin{array}{l}\text { Relative difference in meansł } \\
\text { Bonferroni corrected }\end{array}$ & $-6 \cdot 6$ & $\begin{array}{r}-9 \cdot 0,-4 \cdot 2 \\
-10 \cdot 1,-3 \cdot 1\end{array}$ & $-7 \cdot 0^{\star \star}$ & $\begin{array}{r}-9 \cdot 1,-4 \cdot 7 \\
-10 \cdot 1,-3 \cdot 6\end{array}$ & $-4 \cdot 1$ & $\begin{array}{l}-6 \cdot 9,-2 \cdot 2 \\
-8 \cdot 2,-1 \cdot 3\end{array}$ & $-4 \cdot 4^{\star \star}$ & $\begin{array}{l}-7 \cdot 2,-4 \cdot 6 \\
-8 \cdot 5,-4 \cdot 7\end{array}$ \\
\hline
\end{tabular}

SDS, standard deviation score.

${ }^{*}$ Bonferroni adjustments account for the twenty-four comparisons given in the table. This correction is potentially highly conservative in the presence of a positive correlation between outcomes.

† All models account for clustering by school.

‡Differences between the 2011 (Energized) and 2006 (younger) and 2004 (older) historical control children.

$\S$ Adjusted for age in months, ethnicity and socio-economic status.

|| Differences between the 2011 (Energized) and historical Canterbury comparison children.

I Adjusted for age in months, sex and socio-economic status.

${ }^{\star *}$ Adjusted for ethnicity and socio-economic status.

thereby indicating a possible beneficial effect of the Energize programme on children's aerobic fitness. The information of the Canterbury children did not include anthropometric or ethnicity information for all the children. We were able to account for clustering by school and age, sex and SES. As European children have a lower BMI than Māori children and there were a lower proportion of Māori children in the Canterbury sample (11\%), we speculate that the Canterbury children would run faster than the 2011 Waikato children, who were one-third Māori.

In NZ children, relative poverty and Māori ethnicity compared with non-Māori ethnicity are factors associated with rapid weight gain and a high prevalence of obesity ${ }^{(2,31)}$. A recent review ${ }^{(5)}$ has found strong evidence that community and school obesity prevention programmes over $1-3$ years are associated with a reduction in the rate of weight gain in children. The authors of this review emphasised the need for publications to capture outcomes in relation to the measures of equity and move towards 'identifying how effective interventions can be embedded within health and education' systems. The Energize programme addresses these equity issues because all schools and, therefore, all children in the region are included. Furthermore, in the period of the intervention, the socio-economic conditions of the children had worsened and child poverty had increased ${ }^{(33)}$. Project Energize is, therefore, an intervention that may help reduce the impact of socioeconomic pressure on children. Furthermore, the programme now (2013) has ongoing commitment from the District Health Board and is embedded in the culture of the schools ${ }^{(34)}$.
We believe that the multiple positive findings of the present study reflect the importance of a whole-school approach, clear agreements with schools, within-school coordination, linkage with curriculum and professional development for teachers, working with schools, early intervention ${ }^{(35)}$, and involvement of families and the wider school community. The apparently greater impact among the younger children than among the older children may reflect the evolution of a supportive school environment ${ }^{(36)}$, 'Energized' for up to 4 years before the child started school. The culture and expectations of schools, teachers, children and families have undergone progressive favourable changes due to the escalating engagement with the goals of the programme.

The major limitations of this evaluation are the lack of a contemporaneous comparison group and the inability to quantify the intervention dose by school. A challenge for translational research arises when the intervention is of 'whole-population' nature for the population of interest. Strenuous nationwide attempts to identify appropriate concurrent and similar comparison groups have been unsuccessful. The National Health Surveys measure child body size, and we await the publication of the 2010-11 findings, so that the time trends of NZ and the Waikato region could be compared with those of other regions of NZ. We observed that the 'Healthy' 3-year intervention in twenty-one schools ${ }^{(37)}$ resulted in a concomitant reduction of overweight and obesity ( $\geq 85$ th centile) in the control and intervention schools, but a reduction of BMI $z$-score in the intervention schools implies a change in the shape of the population curve in a favourable direction. 
The challenge of dose quantification is common in many studies of this type, and in general, it is considered as an ongoing challenge for researchers ${ }^{(5)}$. Dose quantification problems lead to the frustration of knowing that a programme may have been effective, and teasing out the key components involved in the success of a programme or identifying redundant or ineffective components becomes impossible as needs of individual schools change with time.

Another limitation is that the children measured in 2011 were not exactly the same age as those in the historical comparison groups and that children do not grow at a steady rate. The age difference has been accounted for, to a certain extent, in the analysis and the use of BMI SDS accounts for sex and age.

The intervention unit is the school, and all children receive the intervention whether or not they agree to participate in the measurement sessions. Within-school child participation bias for an individual measurement is a possible limitation, but all schools that were invited agreed to participate, classes were chosen to participate based on the dominant age of the children and all children in a selected class were invited to be measured. The relatively large study sample was representative of the 2006 census of Waikato population by age, SES and ethnicity.

The Energize programme can be applied to other areas. Two clusters of schools outside the Waikato region are in the process of implementing the Energize programme with support from Sport Waikato. Others are investigating the feasibility of translation into areas nationally and internationally. We believe that the key to the success of the Energize programme is the ongoing training and operation of the Energizers as a team that collectively contributes to the continual development and refinement of activities and resources. The relationship of each Energizer with his or her schools is integral to success. 'Brand' Energize operates within a strict and consistent set of principles around sponsorship and activities. For example, if school sporting events include the sale of unhealthy foods, Energizers will not attend or are offered practical alternatives.

\section{Conclusions}

A long-term regional school-based programme (Energize) is associated with secular reductions in the prevalence of overweight and obesity and gains in physical fitness, across ethnic groups and SES. Besides immediate benefits for individual children, this may reduce their future risk of developing obesity, diabetes and other diseases in adulthood. Long-term, national and regional statistics for body size and nutrient intake will reflect the success of visionary programmes such as Energize.

\section{Acknowledgements}

The authors thank the children, parents, teachers, Energizers and the members of the evaluation reference group for their participation and guidance. The Waikato District Health Board funded the Project Energize programme and its evaluation. The Ministry of Health, NZ, and the Auckland University of Technology contributed to the funding of the evaluation.

The authors' contributions are as follows: E. R. was responsible for study conception and design, data acquisition and interpretation, manuscript drafting and critical revision and is the corresponding author; S. M. was involved in study conception and design, data acquisition, critical revision and final draft approval for submission; V. O. and A. C. V. were responsible for data analysis and interpretation, critical revision and final draft approval for submission; $M$. H. was involved in data interpretation, critical revision and final draft approval for submission; D. S. was responsible for study conception and design, data interpretation, critical revision and final draft approval for submission; D. G. was involved in study conception and design, data acquisition and interpretation, critical revision and final draft approval for submission.

The authors report no conflicts of interest and have no financial disclosures.

\section{References}

1. Cole TJ, Flegal KM, Nicholls D, et al. (2007) Body mass index cut offs to define thinness in children and adolescents: international survey. BMJ 335, 194.

2. Ministry of Health (2008) A Portrait of Health: Key Results of the 2006/07 New Zealand Health Survey. Wellington: Ministry of Health.

3. Ministry of Health (2003) A Portrait of Health: Key Results of the 2002/2003 New Zealand Health Survey. Wellington: Ministry of Health.

4. Sharma M (2006) School-based interventions for childhood and adolescent obesity. Obes Rev 7, 261-269.

5. Waters E, de Silva-Sanigorski A, Hall Belinda J, et al. (2011) Interventions for preventing obesity in children. Cochrane Database of Systematic Reviews, issue 12, 1-212.

6. Sharma M (2007) International school-based interventions for preventing obesity in children. Obes Rev 8, 155-167.

7. Glasgow RE, Magid DJ, Beck A, et al. (2005) Practical clinical trials for translating research to practice: design and measurement recommendations. Med Care 43, 551-557.

8. Green LW, Glasgow RE, Atkins D, et al. (2009) Making evidence from research more relevant, useful, and actionable in policy, program planning, and practice slips "twixt cup and lip". Am J Prev Med 37, S187-S191.

9. Glasgow RE (2008) What types of evidence are most needed to advance behavioral medicine? Ann Behav Med 35, 19-25.

10. Graham D, Appleton S, Rush E, et al. (2008) Increasing activity and improving nutrition through a schools-based programme: Project Energize. 1. Design, programme, randomisation and evaluation methodology. Public Health Nutr 11, 1076-1084.

11. Cole TJ, Freeman JV \& Preece MA (1995) Body mass index reference curves for the UK, 1990. Arch Dis Child 73, 25-29.

12. Rush E, Reed P, McLennan S, et al. (2012) A school-based obesity control programme: Project Energize. Two-year outcomes. Br J Nutr 107, 581-587.

13. Olds TS, Tomkinson GR, Ferrar KE, et al. (2010) Trends in the prevalence of childhood overweight and obesity in Australia between 1985 and 2008. Int J Obes 34, 57-66. 
14. Townsend N, Rutter H \& Foster C (2012) Evaluating the evidence that the prevalence of childhood overweight is plateauing. Pediatr Obes 7, 343-346.

15. University of Otago and Ministry of Health (2011) A Focus on Nutrition: Key Findings of the 2008/09 New Zealand Adult Nutrition Survey. Wellington: Ministry of Health.

16. Simmons D, Rowan J, Reid R, et al. (2008) Screening, diagnosis and services for women with gestational diabetes mellitus (GDM) in New Zealand: a technical report from the National GDM Technical Working Party. $N Z$ Med J 121, $74-86$.

17. National Women's and Auckland District Health Board (2011) National Women's Hospital Annual Clinical Report 2010. Auckland: National Women's, Auckland District Health Board.

18. Albon HM, Hamlin MJ \& Ross JJ (2010) Secular trends and distributional changes in health and fitness performance variables of 10-14-year-old children in New Zealand between 1991 and 2003. Br J Sports Med 44, 263-269.

19. Hong SW \& Hamlin MJ (2005) Secular trends and contemporary differences in physique and health-related fitness levels of 11-12 year-old South Korean and New Zealand children. Southeast Asian J Trop Med Public Health 36, $1339-1345$.

20. Kessler R \& Glasgow RE (2011) A proposal to speed translation of healthcare research into practice: dramatic change is needed. Am J Prev Med 40, 637-644.

21. Ministry of Education (2011) Deciles information. http:// www.educationcounts.govt.nz/directories/list-of-nz-schools (accessed February 2011).

22. Cureton KJ, Boileau RA, Lohman TG, et al. (1977) Determinants of distance running performance in children: analysis of a path model. Res $Q \mathbf{4 8}, 270-279$.

23. Disch J, Frankiewicz R \& Jackson A (1975) Construct validation of distance run tests. Res $Q$ 46, 169-176.

24. Krahenbuhl GS, Pangrazi RP, Burkett LN, et al. (1977) Field estimation of $\mathrm{VO}_{2}$ max in children eight years of age. Med Sci Sports 9, 37-40.

25. Mitchell B, McLennan S, Latimer K, et al. (2011) Improvement of fundamental movement skills through support and mentorship of class room teachers. Obes Res Clin Pract 7 , e230-e234
26. Freeman JV, Cole TJ, Chinn S, et al. (1995) Cross sectional stature and weight reference curves for the UK, 1990. Arch Dis Child 73, 17-24.

27. R Development Core Team (2011) $R$ : A Language and Environment for Statistical Computing. Vienna: R Development Core Team.

28. Doak CM, Visscher TL, Renders CM, et al. (2006) The prevention of overweight and obesity in children and adolescents: a review of interventions and programmes. Obes Rev 7, 111-136.

29. Ministry of Health (2003) NZ Food NZ Children, Key Results of the 2002 National Children's Nutrition Survey. Wellington: Ministry of Health.

30. Clinical Trials Research Unit and Synovate (2010) A National Survey of Children and Young People's Physical Activity and Dietary Behaviours in New Zealand: 2008/09 - Key Findings. Wellington: Ministry of Health.

31. Ministry of Health (2012) The Health of New Zealand Children 2011/12: Key Findings of the New Zealand Health Survey. Wellington: Ministry of Health.

32. Tomkinson GR \& Olds TS (2007) Secular changes in pediatric aerobic fitness test performance: the global picture. Med Sport Sci 50, 46-66.

33. Perry B (2012) Household Incomes in New Zealand: Trends in Indicators of Inequality and Hardship 1982 to 2011. Wellington: Ministry of Social Development.

34. Rush EC, Graham D, McLennan S, et al. (2011) An evaluation of nutrition and physical activity in Waikato schools. Project Energize: June 2008 to June 2011. http://www.sportwaikato. org.nz/files/PE\%20June\%2008\%20to\%20June\%2011\% 20final\%20exec\%20summary.pdf (accessed May 2013).

35. Shonkoff JP, Boyce WT \& McEwen BS (2009) Neuroscience, molecular biology, and the childhood roots of health disparities: building a new framework for health promotion and disease prevention. JAMA 301, 2252-2259.

36. Sallis JF \& Glanz K (2009) Physical activity and food environments: solutions to the obesity epidemic. Milbank $Q \mathbf{8 7}$, $123-154$

37. Foster GD, Linder B, Baranowski T, et al. (2010) A schoolbased intervention for diabetes risk reduction. $N$ Engl J Med 363, 443-453. 